has contributed to the misreading. I have discussed "Spot the difference" in the original version with many children and adults in a variety of multiracial settings, and nobody has previously read the images in this way.

But whatever the source of the problem, would be grateful if you would reassure Mrs Baklanova that the character is supposed to be white in both images, and that no transformation of the sort she describes was intended.

PHILIP BOYS

$\approx$
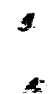
In reply-I have looked intensely at the Baklanova sees. I have also shown it to several colleagues. No one picked up the point made by Mrs Baklanova, which of course may mean that we are all insensitive to $=\quad$ racist nuances.

An alternative viewpoint is as follows: it is not obvious to me that the man in the top (before) picture is indeed black (his skin colour is about the same as that of the man banging on the vending machine). The policeman also is much darker in the top than in the bottom drawing. In fact it is not apparent at all to me that the man in question in the top drawing is meant to be black. Perhaps the duller colours in most of the figures in the top were meant to convey a sense of unhealthy, almost jaundiced skin pallor rather than any racial association (unlike the woman next to him whose features are plainly black in both drawings)

In fact, if one is concerned about transformations between the two drawings, it can be seen that the front passenger in the bus at the top is a male, but a female in the bottom picture; the black woman's hair is "flat-top" style in the top, but less styled in the bottom; the vending machine banger in the top has dark hair, but red in the bottom. And so on.

Mercifully, no one has yet suggested that these differences mean that the artist was making sexist or "hairist" points. Rather, the overall differences between the two pictures are, as $\mathrm{Mr}$ Boys explains, intended to convey a general sense of "smoking = drab and boring", and "non-smoking = alive and happy". Perhaps then, Mrs Baklanova's belief that one particular example of these transformations (assuming for a moment that the man at the top is in fact black) is manifestly significant may be overinterpretive.

Ironically, it occurs to me that nonEuropeans, in an equally over-sensitive way, could interpret her parenthetical remark "in Europe at least" as being a gratuitous piece of mild racism itself, implying that only Europeans would be attuned enough to see the racist differences she claims to see.

SIMON CHAPMAN

Deputy Editor

\section{Overlapping publications}

To the Editor - I would like to apologise for the almost simultaneous publication of two manuscripts with similar titles and overlapping content in Tobacco Control and the American fournal of Health Promotion. ${ }^{1,2}$ I take full responsibility for this.

The piece in the American fournal of Health Promotion was intended as a "how to" guide for practitioners, whereas the article in Tobacco Control was intended as the definitive "Quit and Win" outcome paper for a primarily scientific audience. The "how to" guide was literally an afterthought. Part of our purpose was to achieve greater dissemination to practitioners of material contained in a contest guide prepared in conjunction with the Minnesota Heart Health Program education communities. ${ }^{3}$ The listing of Terry Pechacek and Jerry Fruetel as co-authors was primarily to recognise their contributions to the contest guide from which much of the manuscript content was taken.

The "how to" manuscript was submitted to the Innovative Programs and Techniques section of the Practitioner's Forum of the American fournal of Health Promotion. This forum is "designed to provide practitioners with succinct practical information." In contrast with regular articles, these brief manuscripts were, at the time of submission, limited to only 1200 words. The original draft of the "how to" guide was entitled "A practical guide to implementing community Quit and Win contests". Overlap between this manuscript and the Tobacco Control article at this point was virtually nil

The American fournal of Health Promotion expressed interest in the "how to" manuscript but required extensive revisions including a change in the title, a less general "how to" focus, more information on the actual contests, and inclusion of some outcome data. In responding to the publisher and reviewers, there was now some overlap with the Tobacco Control article, despite the fact that the purpose and the intended target audiences were both clearly different. Furthermore, the manuscript had now been expanded to 1800 words, thus making it more nearly equivalent to a full article. Although I raised the issue of possible overlap in a letter to the publisher of the American Fournal of Health Promotion, I failed to raise this issue with the editor of Tobacco Control. I wish that I had done so.

In conclusion, I am very sorry if the almost simultaneous publication of these two manuscripts has detracted in any way from the Tobacco Control article.

HARRY A LANDO Minneapolis, Minnesota, USA

1 Pechacek TF, I ando HA, Nothwehr F, Lichtenstein $\mathrm{E}$. Quit and Win: a community-wide tenson. Tobacco approach to smoking

2 Lando, HA, Pechacek, TF, Fruetel, J. The Minnesota Heart Health Program community Quit and Win contests. Am $\mathcal{F}$ Health Promotion 1994; 9: 85-7, 124 .

3 Heartland Community Health Programs. Quit $\mathcal{E}$ Win contest : process guide for a community smoking-cessation campaign. Minnesota: University of Minnesota, 1989

We encourage authors to consult and adhere to the guidelines on duplicate or redundant publication guidelines on duplicate or redundant publication cal fournal Editors, which have been published in cal fournal Editors, which have 